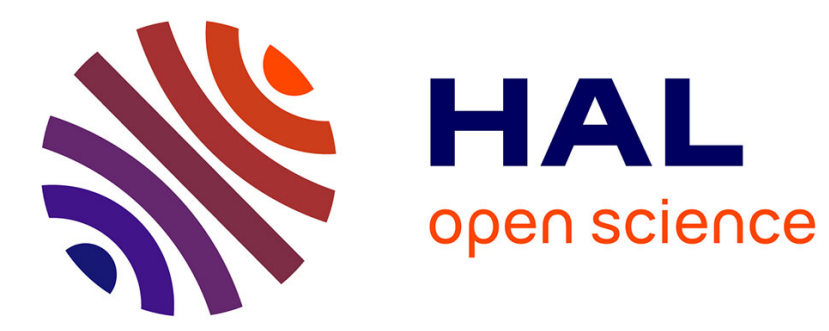

\title{
IMPROVED SUPPRESSION OF UNCORRELATED BACKGROUND NOISE WITH THE STSF TECHNIQUE
}

J. Hald, K. Ginn

\section{> To cite this version:}

J. Hald, K. Ginn. IMPROVED SUPPRESSION OF UNCORRELATED BACKGROUND NOISE WITH THE STSF TECHNIQUE. Journal de Physique IV Proceedings, 1992, 02 (C1), pp.C1-633-C1636. 10.1051/.jp4:19921136 . jpa-00251093

\section{HAL Id: jpa-00251093 https://hal.science/jpa-00251093}

Submitted on 1 Jan 1992

HAL is a multi-disciplinary open access archive for the deposit and dissemination of scientific research documents, whether they are published or not. The documents may come from teaching and research institutions in France or abroad, or from public or private research centers.
L'archive ouverte pluridisciplinaire HAL, est destinée au dépôt et à la diffusion de documents scientifiques de niveau recherche, publiés ou non, émanant des établissements d'enseignement et de recherche français ou étrangers, des laboratoires publics ou privés. 


\title{
IMPROVED SUPPRESSION OF UNCORRELATED BACKGROUND NOISE WITH THE STSF TECHNIQUE
}

\author{
J. HALD and K.B. GINN \\ Brüel \& Kjøer, Narum Hovedgade 18, DK-2850 Naerum, Denmark
}

\begin{abstract}
The Spatial Transformation of Sound Fields (STSF) technique permits a 3D sound field mapping based on a 2D scan measurement in the near field of a source. By measurement of the cross spectra between a set of references and the cross spectra from each scan position to each of the references, a principal component representation of the sound field is extracted which can be applied for near field holography and Helmholtz' integral equation calculations. Basically, this sound field representation includes only the part of the sound field, which is coherent with the reference signals. More precisely, only "views" of the independent parts of the sound field seen by the references are included. Therefore, provided the references do not pick up the background noise, the background noise will not be part of the sound field model processed by STSF. However, if the background noise is picked up by the reference transducers, it will become part of the model and cause errors in the calculations. In order to overcome this problem, the possibility of using a set of "exclude references" has been implemented in the STSF system. These references should pick up only the uncorrelated background noise to be suppressed in the model
\end{abstract}

\section{SOMMAIRE}

La transformation spatiale des champs sonores (STSF) sert à cartographier en trois dimensions le champ acoustique à partir des mesures obtenues par balayage en deux dimensions dans le champ proche d'une source. En mesurant l'interspectre entre chaque paire de points de référence, et l'interspectre entre chaque point de balayage et chaque point de référence, on obtient une représentation du champ acoustique qui permet d'établir l'holographie du champ proche et de calculer les intégrales de Helmholtz. La représentation du champ acoustique comprend uniquement la partie du champ acoustique qui est cohérente avec les signaux de référence. Par conséquent, si les signaux de référence n'incorporent pas le bruit de fond, celui-ci ne fera pas partie du modèle de champ acoustique traité par la STSF. Mais, si au contraire le bruit de fond est capté par les microphones de référence, il contribuera au modèle et entraînera des erreurs de calcul. Pour pallier ce problème, le système STSF mesure le bruit de fond non corrélé et l'exclut du modèle. 


\section{PRINCIPLE OF STSF}

The principle of the STSF technique is illustrated in Fig. 1. A certain stationarity of the source is assumed and correlation, phase and amplitude information is obtained by measuring the cross spectra during a scan over a plane close to the source under investigation. Based on these cross spectra, an eigenfield (principal component) representation of the sound field is extracted. Any power descriptor of the sound field (e.g. intensity, reactive intensity, pressure, particle velocity) can then be mapped over a three dimensional region extending from the surface of the source to infinity (Fig. 1). The near field is predicted from the scan data using near-field acoustical holography while the more distant field is calculated using Helmholtz' integral equation. In addition to the 3D mapping capability based on 2D measurements, STSF also provides the possibility of performing a simulation of partial source attenuation. The main advantage of the STSF technique compared to similar systems is that STSF can be used on broadband, non-coherent sources [1].

\section{THE USE OF REFERENCE TRANSDUCERS}

Ideally, the cross spectrum from every point to every other point over the scan area would have to be measured yielding an enormous amount of data. However, the amount of data to be measured, stored and processed can be considerably reduced by using some important properties of the cross spectrum matrix to remove redundant information. Since in general the matrix is strongly rank deficient the whole matrix can be constructed from a relatively small number of linearly independent, columns, obtained by measuring the cross spectra from the scan points to a number of reference transducers and the cross spectra between every pair of references [1].

The reference transducers should be placed between the sound source and the scan plane and should be distributed over the scan area. Too few reference transducers will generally misrepresent the sound field as certain important combinations ("views") of the (time) independent partial fields will not be identified. This is illustrated by the following example taken from [1]. An STSF measurement is made over two loudspeakers using a single reference microphone placed on the symmetry plane between the two loudspeakers. The loudspeakers are excited by two identical, independent noise generators which are adjusted to produce equal sound pressure levels at the reference. Thus, the total sound field consists of two coherent, mutually uncorrelated, partial fields. However, the use of one reference provides only one "view" of the two partial fields and therefore does not allow the two fields to be distinguished. Only the equal-amplitude, in-phase view is obtained leading to an apparent in-phase action of the loudspeakers and as a consequence a strong interference pattern (Fig. 2). To include both partial fields, a second reference needs to be added. Furthermore, the second reference must have a "view" of the source which is different to that of the first reference. The solid curve in Fig. 2 shows the sound pressure level calculated from a measurement involving two references. Notice that the spurious interference pattern has been avoided. If one or more partial sources can be identified before the references are selected then references can be positioned to pick up individual partial fields.

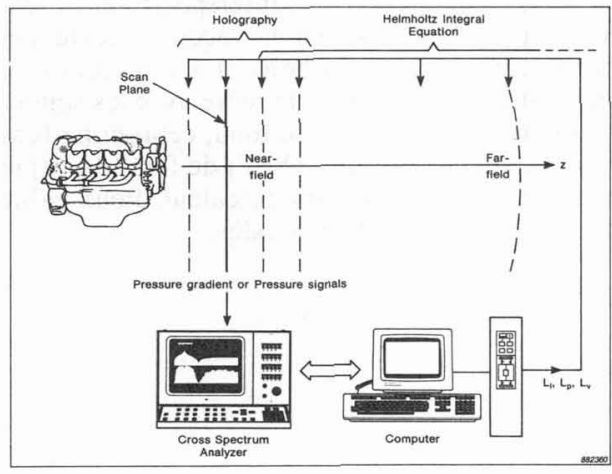

Fig. 1. Principle of STSF based on Multichannel Analysis System Type 3550

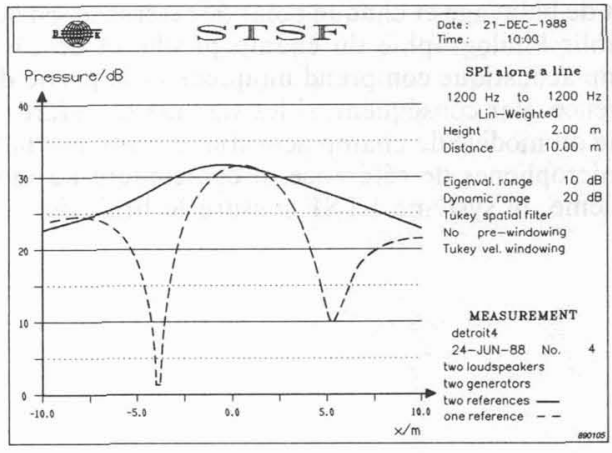

Fig. 2. Calculated sound pressure level: one reference (dashed), insufficient references; two references (solid) sufficient references 


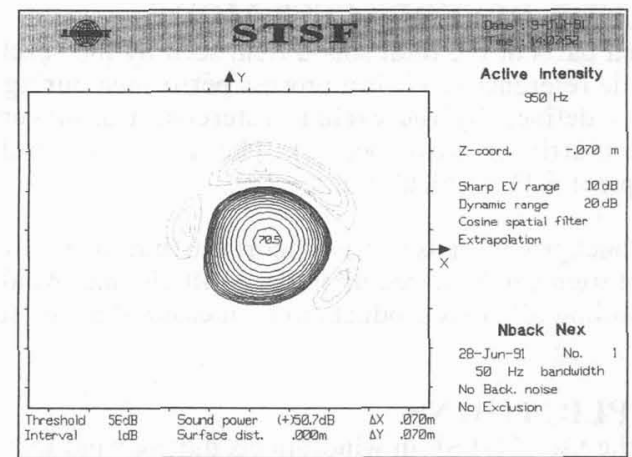

Fig. 3. Principal source on; No background noise, Exclude reference mode not used

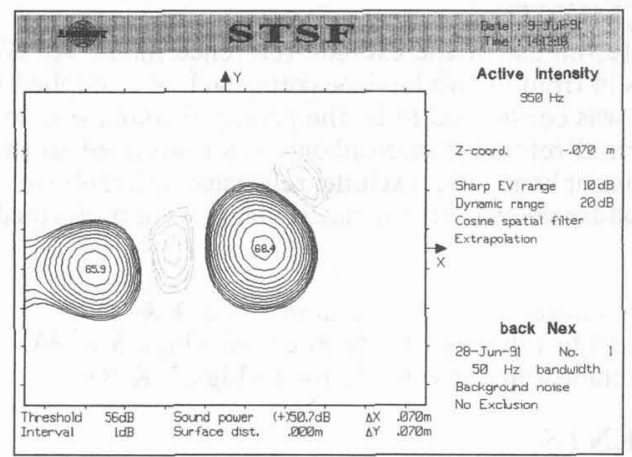

Fig. 5. Principal source on; Background noise present, Exclude reference mode not used

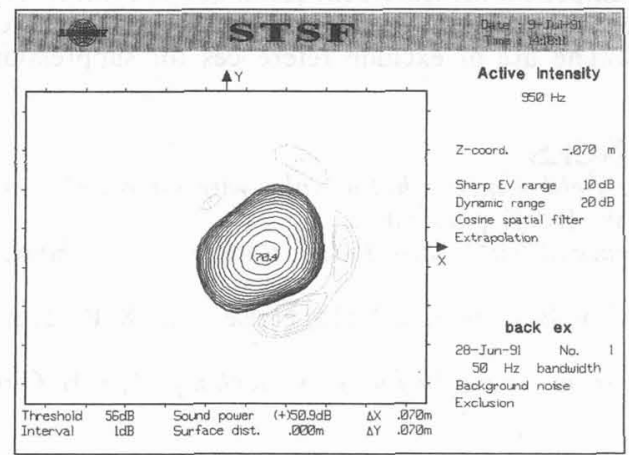

Fig. 7. Principal source on; Background noise present, Exclude reference mode used

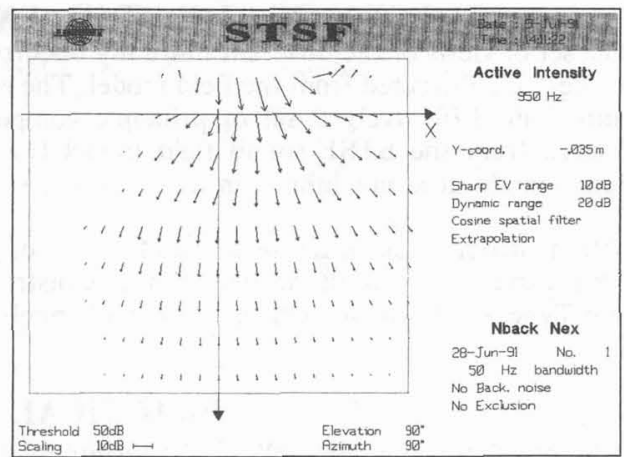

Fig. 4. Principal source on; No background noise, Exclude reference mode not used

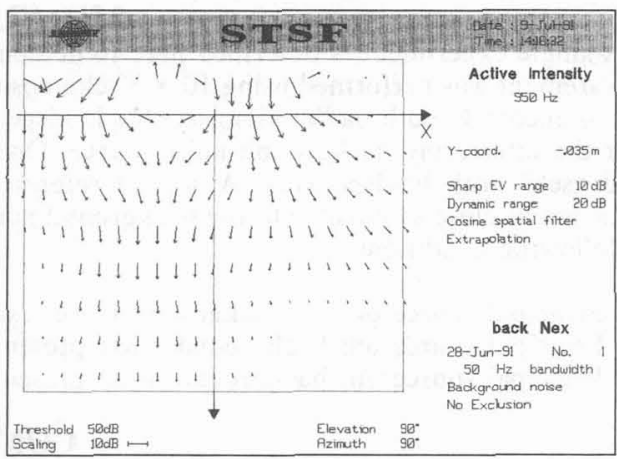

Fig. 6. Principal source on; Background noise present, Exclude reference mode not used

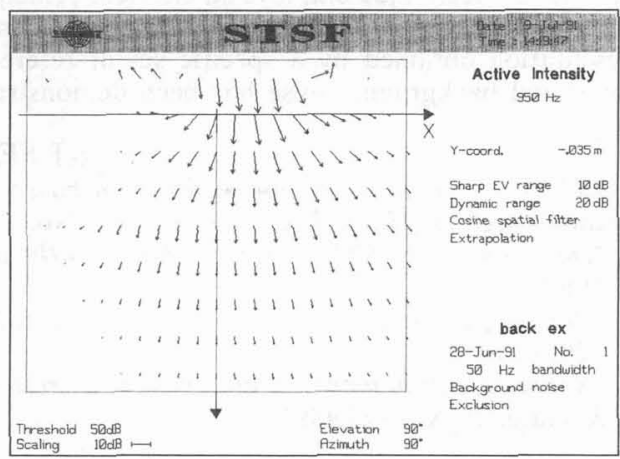

Fig. 8. Principal source on; Background noise present, Exclude reference mode used 


\section{THEORY OF THE STSF “EXCLUDE REFERENCES" MODE}

The set of views of the different mutually uncorrelated parts of the total sound field seen by the "exclude references" is subtracted from the field model. The exclude reference mode is a process performed during the measurement. Effectively a set of principle components defined by the exclude reference transducers is subtracted from the STSF sound field model (i.e. the matrix of cross-spectra). The use of the exclude reference mode does not inhibit in any way the subsequent STSF calculations.

To obtain sufficient accuracy in the subtraction of the background noise, it is important that all reference signals are measured simultaneously. Suitable instrumentation can be based upon the Multichannel Analysis System Type 3550 , which enables up to 16 channels including all cross products to be measured at the same time.

\section{PRACTICAL APPLICATIONS}

A major practical application of this technique is in the use of STSF in windtunnels during wind induced noise testing of motor vehicles. Often, the fan noise of the windtunnel itself is the principal undesirable noise source. Another application is the investigation of tyre/road noise under running conditions. In this case the noise due to the engine can be significantly suppressed by placing an exclude reference in the engine compartment.

\section{MEASUREMENTS}

A single experiment is described here to demonstrate the use of the exclude reference mode. An STSF measurement was performed using $10 \times 8$ scan positions in front of two loudspeakers, each one supplied with its own uncorrelated broadband noise. One loudspeaker was considered to be the principal sound source, the other the interfering background noise source. One normal reference microphone was positioned so that it could "see" both loudspeakers. A second reference microphone, the exclude reference microphone, was positioned as close as possible to the background noise loudspeaker. Three measurements were performed for the following conditions:

1. Principal source on; no background noise; exclude reference mode not used (Figs. 3 \& 4).

2. Principal source on; background noise present; exclude reference mode not used (Figs. 5 \& 6).

3. Principal source on; background noise present; exclude reference mode used (Figs. 7 \& 8).

\section{COMMENTS}

From Figs. $5 \& 6$ and $9 \& 10$ it can be seen that the exclude reference mode accurately reconstitutes the unadulterated sound field from the principal sound source. This is seen quantitatively in the total sound power, and qualitatively in the vector plots and in the contour plots.

Variations are due to positioning errors of the scan microphone which was hand-held.

\section{CONCLUSIONS}

The STSF technique employs an efficient principal component measurement technique to achieve a cross spectral representation of the sound field. The technique also includes a validation procedure to evaluate the representation obtained by a specific set of references. The use of exclude references for suppression of uncorrelated background noise has been demonstrated.

\section{REFERENCES}

[1] "STSF - a unique technique for scan based near-field acoustic holography without restrictions on coherence", J. Hald, Technical Review No. 1, 1989, B \& K publication

[2] "Development of STSF with emphasis on the influence of bandwidth; Part I, Background \& theory", J. Hald

[3] "Part II Instrumentation and computer simulation", K.B. Ginn \& J. Hald, Noise Con 88, Proceedings $529,(1988)$

[4] "Source location using accelerometers as reference transducers for the STSF technique", K.B. Ginn \& J. Hald, ICA 89 (1989) 